\title{
The Case Study of Heart Disease at Urban and Rural Communities by Gender and Age in Indonesia in 2018
}

\author{
Mugeni Sugiharto', Lukman Prayitno ${ }^{1}$, Galih Arianto' \\ ${ }^{1}$ Health Researcher, The Center of Research and Development For Humanities and Health Management, \\ Ministry of Health, Republic of Indonesia
}

\begin{abstract}
Introduction: Heart disease is a community health problem. It is expensive to care and cure and leading cause of death in Indonesia. The research aimed to analyze relationship and magnitude of the risk of exposure of heart disease in urban and rural communities according to age and sex factors. Methods: It was quantitative research with cross sectional design. Data came from Indonesia Basic Health Research at 2018 with all household as population. Sample were individuals aged $\geq 15$ years. It used chi square and estimate risk analysis. Results: Heart disease was higher in urban areas, especially $54,6 \%$ women were more exposed to heart disease than $45,4 \%$ men. Also elderly group was the highest $(65,8 \%)$ than other group. There were $66.7 \%$ elderly men and $65.0 \%$ women risk to exposed heart disease than other groups. There was a significant relationship between gender, age and region with heart disease cases. The exposure risk of heart disease for men in urban areas were 1.4 times greater than rural. The urban elderly group were 1.9 times greater than rural. The urban elderly men group were 2 times greater than rural. The urban elderly women group were 1.8 times larger than rural. Conclusion: Heart disease in urban areas was higher than rural areas. Women had more risk of heart disease. Elderly women group had highest risk than other age groups.
\end{abstract}

Keywords: Heart disease, urban, rural, women, men. elderly

\section{Introduction}

Heart disease is a non-communicable disease caused by heart and blood vessel disorders. ${ }^{1}$ It occurs in urban and rural communities. It is still the leading cause of death after stroke and hypertension in Indonesia. ${ }^{2}$ Heart disease is the number 1 killer disease in the world. It has also begun to trend towards a younger age, especially in groups who have low physical activity, which mostly occurs in urban communities. ${ }^{3,4}$ In the United States, it reached 43.8\% deaths. ${ }^{5}$ Poland was classified as a country with CVD high-risk mortality (i.e., CVD deaths $>450 / 100,000$ in men and $>350 / 100,000$ in women). ${ }^{6}$ Mortality in rural areas was higher than in urban areas. ${ }^{7,8}$ Male deaths were more height than female. ${ }^{6}$ The prevalence of heart disease among the rural poor was still quite high. ${ }^{9}$ Risk factors in middle-income countries have increased markedly due to the way of working and the transition to sedentary, abusive, and greedy lifestyles. ${ }^{10}$

The quality life of a person was influenced by age and sex because older person would have the lower the body's function both physically and psychologically. ${ }^{11}$ Male tended to have better body functions than women. ${ }^{12}$

In addition, heart disease in Indonesia is still difficult to overcome. It is due to decentralization policies and the low commitment of local governments, unequal health development between provinces in dealing with heart disease and low community independence in preventing heart disease..$^{13,14,15}$ 
People still have not abandoned their health risky eating behavior in urban and rural areas. It make many obesity, diabetes and hypertension that lead to heart disease. ${ }^{16,17}$ This research focused on exploring the relationship and the magnitude of the risk of exposure to heart disease in urban and rural areas by age and sex groups. This study aimed to analyze the relationship and the magnitude of the risk of heart disease exposure in urban and rural communities according to age and sex in Indonesia in 2018.

\section{Methods}

This research obtained ethical permission from the ethics commission of the National Institute Of Health Research and Development, Indonesian Ministry of Health. The ethics permit number was LB.02.01/2/ KE.024/2018. It was a quantitative research with a cross-sectional design. The independent variables were gender, age and region. The dependent variable was heart disease (with answer 1 yes and 2 no). All methods were carried out in accordance with relevant guidelines and regulations. Informed consent was obtained from all participants. If participants were under 18, we got it from parent and or legal guardian.

This research analyzed relationship with chi square test at the level of trust (Confident Interval/ CI) $95 \%$ and the significance level $p<\alpha(5 \%)$. This article also presented a risk estimate analysis or Odds Ratio (OR). It aimed to measure associations of heart disease exposure (risk factors) between urban and rural communities. The population was all households in all provinces in Indonesia (34 Provinces and 514 districts/ cities), 12,915 urban, 17,085 rural. The total sample were 25,000 households. The samples were individuals aged $\geq 15$. The unit of analysis was the household.

Nominal scale of independent variables were area of residence (urban : code 1 and rural : code 2), sex (male code 1 and female code 2), age. Age was based to the Ministry of Health categorical age. It was adolescents (code 1 : age 12-25 years), adults (code 2 : ages $26-45$ years), elderly (code $3:$ aged $46-65$ years) and seniors (code $4:$ age $>65$ years). The dependent variable was heart disease (code 1 : "Yes" and code 2 : "No"). Based on the 2018 Riskesdas guidelines, heart disease was abnormalities in the heart such as coronary heart disease, heart failure (decompensation cordis), valve abnormalities, swelling of the heart muscle. It has been diagnosed by a doctor or clinically. It was characterized by chest pain or discomfort in the chest or heavy chest. Heavy chest was chest feels heavy when it was climbing/ heavy work or walking in a hurry when walking on flat roads or walking long distances. ${ }^{18}$

The data source came from the results of Basic Health Research (Riskesdas) in 2018. Riskesdas 2018 was a type of survey research. The calculation of the sample was according to the Susenas sample. Susenas was carried out by the Indonesian Central Statistics Agency (BPS). It used PPS (probability proportional to size) with linear systematic sampling. It was two Stage sampling.

The data analyzed was the result of weighting (weight case) by BPS, so that the number of respondents analyzed was $193,126,723$ people with 96,248,062 males and 96,878,661 women. Male live in urban areas were 53,221,996. Men live in rural areas were $43,026,066$. Women live in urban area were $53,611,787$. Women live in rural areas were $43,266,874$.

\section{Results}

Riskesdas 2018 specifically asked cases of heart disease in the community, so that the latest cases in the community could be known. The research found that people who were not exposed to heart disease $\geq 97.8 \%$ and those exposed to heart disease were only $\leq 2.2 \%$. They were from adolescence (age 15 
years) to seniors (age $>65$ years) ). Based on their place of residence, the cases of heart disease in urban communities were $61.5 \%$ and in rural communities were $38.5 \%$. In urban area, the number of women who were exposed to heart disease reached $60.8 \%$, which was higher than those who live in rural areas. In urban area, the number of men who were exposed to heart disease reached $62.5 \%$, which was higher than those who live in rural areas.

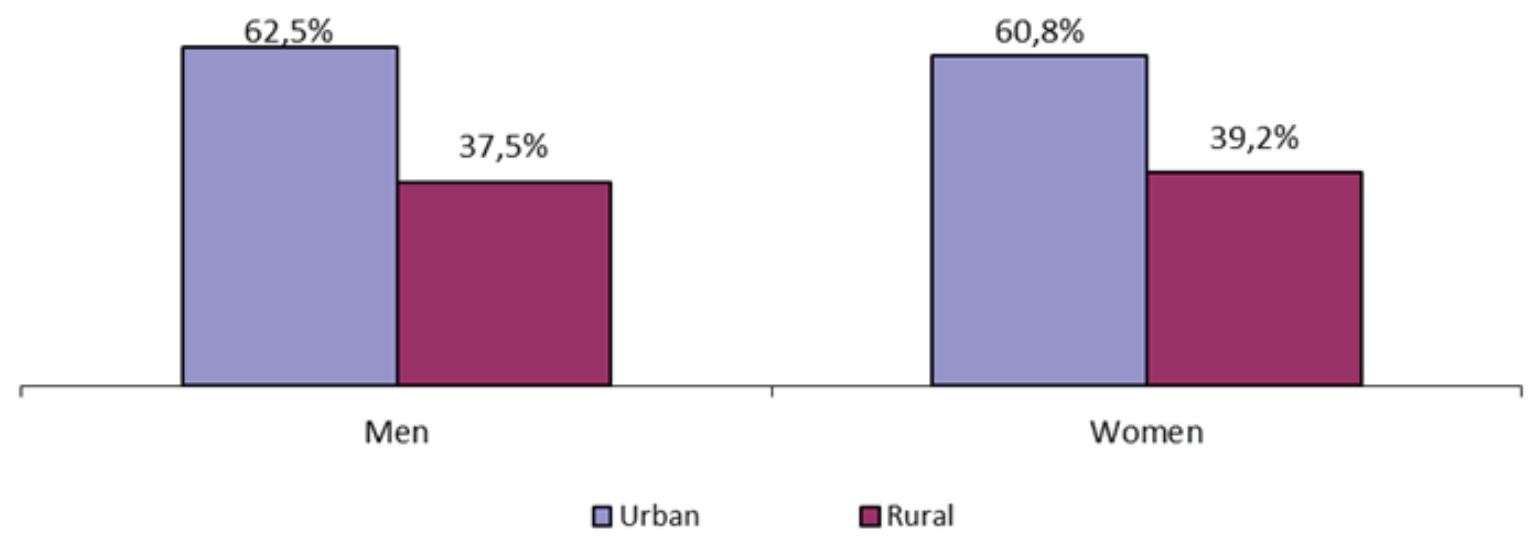

Figure 1. Heart Disease Cases in Men and Women by Area of Residence (Urban and Rural) in Indonesia in 2018

Based on figure 1, in urban communities, it showed that women who were exposed to heart disease were $54.6 \%$. It was higher than men. Men who were exposed to heart disease only $45.4 \%$.
Older people were more at risk of developing heart disease. In urban communities, the senior group (age > 65 years) was the highest group (65.8\%) exposed to heart disease. The elderly group (age 45-65 years) was second group (63.6\%) exposed to heart disease.

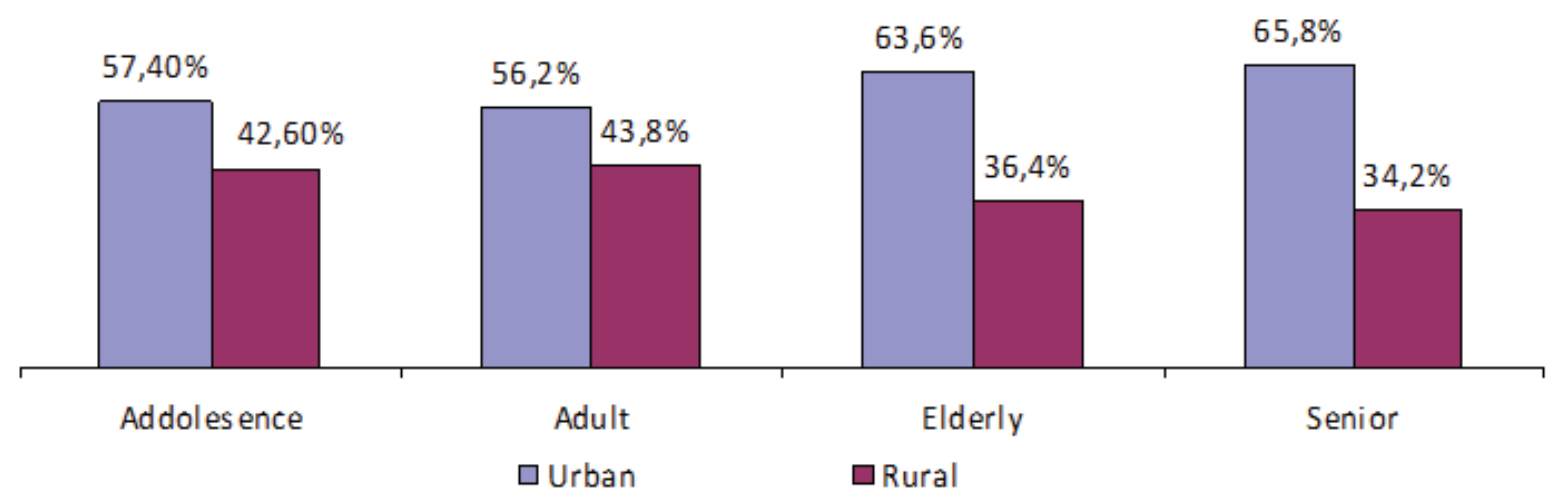

Figure 2. Heart Disease Cases Based on Age Group and Residence Area

Based on figure 2, adolescents were the lowest age group exposed to heart disease in urban area, the male in senior group were $66,7 \%$ exposed to heart disease.
It was the highest group exposed to heart disease. The women in senior group were $65.00 \%$ exposed to heart disease. It was the second group. 


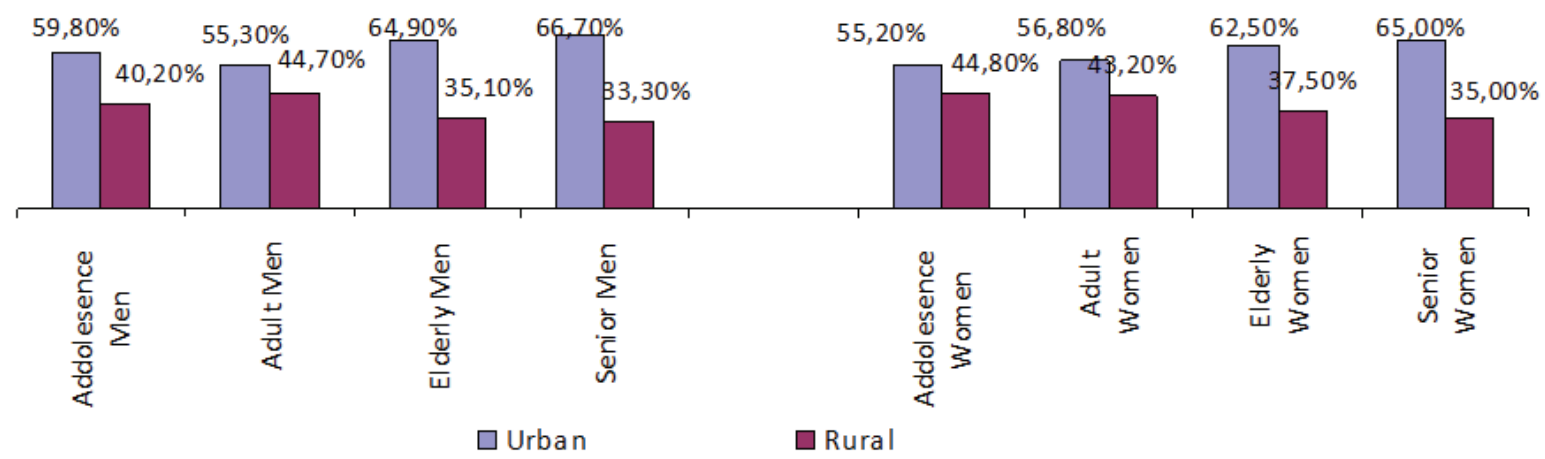

Figure 3. Age Groups of Heart Disease Cases in Men and Women by Region of Residence

Based on figure 3, correlation analysis (Chi (heart disease) showed a significant relationship Square test) between independent variables (age, $\quad \mathrm{p}<\alpha(0.005)$. The results of the estimated risk sex and area of residence) and dependent variable (Estimate Risk or Odds Ratio (OR)) showed as follows :

Table.1. Significance Value and Estimated Risk (OR) of Heart Disease by Gender, Age and Area of Residence

\begin{tabular}{|c|c|c|c|c|c|c|c|}
\hline \multirow{2}{*}{ No } & \multirow{2}{*}{ Variabel } & \multirow{2}{*}{ Residence } & \multicolumn{2}{|c|}{ Diagnosis } & \multirow{2}{*}{ Total } & \multirow{2}{*}{$\begin{array}{c}\text { Sig } \\
(p<\alpha)\end{array}$} & \multirow{2}{*}{ OR } \\
\hline & & & Heart Disease & Healthy & & & \\
\hline A & \multicolumn{7}{|c|}{ Sex } \\
\hline \multirow{2}{*}{1} & Men & urban & 971780 & 52250216 & 53221996 & \multirow{2}{*}{0,000} & \multirow{2}{*}{1,351} \\
\hline & Men & Rural & 584217 & 42441849 & 43026066 & & \\
\hline \multirow{2}{*}{2} & Women & urban & 1170964 & 52440823 & 53611787 & \multirow{2}{*}{0,000} & \multirow{2}{*}{1,256} \\
\hline & Women & rural & 756033 & 42510841 & 43266874 & & \\
\hline $\mathrm{B}$ & \multicolumn{7}{|c|}{ Age Group } \\
\hline \multirow{2}{*}{3} & Adolecent & urban & 192549 & 26582773 & 26775322 & \multirow{2}{*}{0,000} & \multirow{2}{*}{1,031} \\
\hline & Adolecent & rural & 142909 & 20350190 & 20493099 & & \\
\hline \multirow{2}{*}{4} & Adult & urban & 494116 & 44457840 & 44951956 & \multirow{2}{*}{0,009} & \multirow{2}{*}{1,006} \\
\hline & Adult & rural & 385265 & 34861209 & 35246474 & & \\
\hline \multirow{2}{*}{5} & Elderly & urban & 1037352 & 27094708 & 28132060 & \multirow{2}{*}{0,000} & \multirow{2}{*}{1,496} \\
\hline & Elderly & rural & 594037 & 23208640 & 23802677 & & \\
\hline
\end{tabular}


Cont... Table.1. Significance Value and Estimated Risk (OR) of Heart Disease by Gender, Age and Area of Residence

\begin{tabular}{|c|c|c|c|c|c|c|c|}
\hline \multirow{2}{*}{6} & Manula & urban & 418727 & 6555718 & 6974445 & \multirow{2}{*}{0,000} & \multirow{2}{*}{1,914} \\
\hline & Manula & rural & 218040 & 6532652 & 6750692 & & \\
\hline $\mathrm{C}$ & \multicolumn{7}{|c|}{ Sex and Age Group } \\
\hline \multirow{2}{*}{7} & Adolesence men & urban & 95790 & 13496291 & 13592081 & \multirow{2}{*}{, 000} & \multirow{2}{*}{1,153} \\
\hline & Adolesence men & rural & 64469 & 10477247 & 10541716 & & \\
\hline \multirow{2}{*}{8} & Adult Men & urban & 199933 & 22191598 & 22391531 & \multirow{2}{*}{, 000} & \multirow{2}{*}{,967 } \\
\hline & Adult Men & rural & 161650 & 17356103 & 17517753 & & \\
\hline \multirow{2}{*}{9} & Elderly Men & urban & 485207 & 13580650 & 14065857 & \multirow{2}{*}{, 000} & \multirow{2}{*}{1,582} \\
\hline & Elderly Men & rural & 262669 & 11627421 & 11890090 & & \\
\hline \multirow{2}{*}{10} & Senior Men & urban & 190851 & 2981678 & 3172529 & \multirow{2}{*}{, 000} & \multirow{2}{*}{2,000} \\
\hline & Senior Men & rural & 95429 & 2981078 & 3076507 & & \\
\hline \multirow{2}{*}{11} & Adolesence Women & urban & 96759 & 13086482 & 13183241 & \multirow{2}{*}{, 000} & \multirow{2}{*}{,931 } \\
\hline & Adolesence Women & Rural & 78439 & 9872942 & 9951381 & & \\
\hline \multirow{2}{*}{12} & Adult Women & urban & 294183 & 22266242 & 22560425 & \multirow{2}{*}{, 000} & \multirow{2}{*}{1,034} \\
\hline & Adult Women & Rural & 223615 & 17505106 & 17728721 & & \\
\hline \multirow{2}{*}{13} & Elderly Women & urban & 552145 & 13514059 & 14066204 &, 000 & \multirow{2}{*}{1,428} \\
\hline & Elderly Women & Rural & 331367 & 11581219 & 11912586 & & \\
\hline \multirow{2}{*}{14} & Senior Women & Urban & 227872 & 3574040 & 3801917 & \multirow{2}{*}{, 000} & \multirow{2}{*}{1,847} \\
\hline & Senior Women & Rural & 122612 & 3551574 & 3674186 & & \\
\hline
\end{tabular}

Based on table 1, the risk of exposure to heart disease in men who lived in urban areas was 1.4 times greater than those who live in rural areas. The risk of exposure to heart disease in women who lived in urban areas was 1.3 times greater than those who live in rural areas. The risk of having heart disease based on age showed that the older person, both men and women, was the greater the risk of developing heart disease. The senior group in urban area was a group that has a risk of exposure to heart disease by 1.9 times higher risk than those living in rural areas. The risk of exposure to heart disease based on sex and age showed that elderly men in urban areas had 2.00 times higher risk of heart disease than those who live 
in rural areas. Elderly women in urban areas had 1.8 times higher risk of heart disease than those who live in rural areas. In general, people in urban areas had a higher risk of heart disease than those who lived in rural areas. It was especially for women. The older person was more risk to exposed of heart disease.

\section{Discussion}

Heart disease had a significant relationship with population demographic factors, such as age and gender. ${ }^{19}$ Currently, heart disease is found in both urban and rural areas. Men and women who lived in urban areas experience higher cases than those who lived in rural areas. The results of the risk estimation or odds ratio (OR) showed that men and women who lived in urban areas have a greater risk of developing heart disease than those who lived in rural areas. According to several articles, it was caused by differences in the eating patterns of urban and rural communities. It was very influential to trigger heart disease cases. The diet of urban communities caused more cases of obesity, diabetes, and lack of physical activity, less balanced nutrition, and air pollution. ${ }^{20}$ Apart from that, unhealthy dietary behavior in urban communities could trigger heart disease. ${ }^{16}$ The smoking habit of urban communities was also a trigger for high cases of heart disease in urban areas. ${ }^{21}$ High-intensity working behavior in cities could triggers stress to heart disease. ${ }^{3}$ Low physical activity in urban communities is caused of using more modes of transportation for activities outside the home such as going to the market, to offices and other activities. ${ }^{3}$, $17,22,23$

The results of the 2018 Riskesdas showed that urban people ate more foods that were risky to health, such as eating fatty/ cholesterol foods more than once a day reached $43.6 \%$ while rural people only $39.5 \%$, eating salty food more than once a day reached $30.5 \%$ while the rural community was only $28.7 \%$, eating sweet food more than once a day reached $62.02 \%$ while the rural community was $60.37 \%$, and the proportion of eating meat, chicken, processed fish with preservatives was more than once a day in urban communities it reached $5.5 \%$ while in rural communities it was only $4.1 \% .{ }^{4}$ Due to a health risk diet, urban people were more obese than rural communities ${ }^{16,17}$ and cases of hypertension in urban areas $^{3,24}$ The proportion of urban people experiencing obesity was $42.9 \%{ }^{25}$ and almost half of the adult urban population was obese. ${ }^{3}$

Heart disease cases had a significant relationship to gender $(p<\alpha(0.005))$. Odd ratio value of heart disease cases in urban women was higher than men. These findings were in line with the results of another research which states that in the last 10 years, heart disease has been found to be higher in women who live in cities. ${ }^{21}$ The high number of heart disease cases in women was because more women were obese, diabetes and hypercholesterolemic. than men. ${ }^{26}$ The prevalence of heart disease and tumors was higher in women. ${ }^{27}$ Women were more susceptible to heart disease and stroke. ${ }^{27}$

This study also analyzed the relationship between age and the occurrence of heart disease cases. Statistically it was found that there was a significant relationship $\mathrm{p}(0.000)<\alpha(0.005)$ between the variation in the age group and heart disease. Heart disease was more common in the senior group than elderly, adults and adolescents. This was in line with another study which states that heart disease was more prevalent in older age groups, especially those living in urban areas. ${ }^{21}$ and the older person is more risk of developing heart disease. ${ }^{28}$

The aging factor could have a significant effect $(p$ value $=0.001)$ in reducing the quality of life. ${ }^{26}$ The older person would experience an increase in total cholesterol levels, an increase in excess fat content which results in metabolic syndrome, thus increasing the risk of heart disease. ${ }^{29}$ Aging factor influenced the 
function of the heart, such as : decreasing elasticity and widening of the aorta, thickening and stiffness of the heart valves, increasing connective tissue. It is resulting in heart failure in the elderly. ${ }^{30}$ According to one article, that men aged $>45$ years were at risk of developing heart disease. ${ }^{5}$

\section{Conclusion}

Heart disease was significantly affected by place of residence (urban and rural), sex and age group. Urban communities had higher risk of heart disease exposure than rural communities. In urban communities, women showed a higher risk of heart disease exposure than men.

In the age group, the older people had higher risk of developing heart disease. The group of seniors (> 65 years) who lived in urban areas had a risk of heart disease exposure 1.9 times than group of seniors who lived in rural areas. Elderly men (46-65 years) who lived in urban areas had a risk of heart disease exposure 2 times than group of elderly men who lived in rural areas. Elderly women (46-65 years) who lived in urban areas had a risk of heart disease exposure 1,8 times than group of elderly women who lived in rural areas. Men and women in adolescents (age 12-25 years) group who lived both in urban and rural areas had the lowest risk of heart disease exposure.

\section{Suggestion}

Heart disease affect more urban communities, especially women and the elderly. It is also important to watch out adolescents group because they become a part of being exposed to heart disease. Therefore, it is time for the local government and the communities to support government policies in controlling heart disease prevention. It is through increasing community participation in a clean, healthy lifestyle, avoiding health-risky diets and increasing physical activity through regular exercise. It must include all age group. In addition, it is important for local governments to optimize the implementation of the decentralization policy in the health sector in the prevention of heart disease in Indonesia.

\section{Declarations}

\section{Ethics Approval and consent to Participate}

This Manuscript get ethics approval from National Institute of Health Research and Development, Indonesian Ministry of Health. The ethics permit number was LB.02.01/2/KE.024/2018.

\section{Consent for Publication}

As another health scientific research, enumerator get consent to participate and consent for publication from respondents. Enumerator must read informed consent to the respondents. Before enumerator collect data, respondents must agree by signing in the form of “Approval (Interview) After Explanation”.

\section{Availability of Data and Materials}

The datasets used and/or analysed during the current study available from the corresponding author on reasonable request. All data generated or analysed during this study are included in this published article.

Competing Interest: We do not have any competing interests.

Funding: Our Institution, Indonesian Ministry of Health, did this research. There are not any funding in making this article.

\section{Author's Contribution}

All the author work together. We have equal contribution. All of us are the main contributors.

\section{Acknowledgement}

Authors would like to thank to the Head of National Intitute Of Health Research and Development, the Head of The Center of Research and Development 
For Humanities and Health Management of the Indonesian Ministry of Health, the Data Management Team of the National Institute Of Health Research and Development, the Indonesian Ministry of Health.

\section{References}

1. WHO. 2013. About Cardiovascular diseases. World Health OrganizLation. Geneve. [cited 2020 Dec 12]. Available from: http://www.who. int/cardiovascular_diseases/about_cvd/en/

2. WHO. (2017). W Heart Day 2017. Retrievedfrom http:// www.who.int/cardiovascular_diseases/worldheart-day-2017 (10 Januari 2021).

3. Bijukshe S, Bangdel DR. Risk Factors of Cardiovascular Disease between Urban and Rural Adult Population. International Journal of Caring Sciences. January-April 2018; 11 (1) : 71 $-86$.

4. Indonesian Ministry of Health. (2018). Main Results of Riskesdas 2018. Retrieved from http:// www. depkes.go.id/resources/download/info.../ hasil-riskesdas-2018.

5. Emilia JB, Salim SV, Clifton WC, Alana MC, et al. Heart disease and stroke statistics-2018 update: A report from the American Heart Association. 2018. Circulation, 137 (12), e67. https://doi.org/ 10.1161/CIR.0000000000000558

6. Massimo FP, Arno WH, Stefan A, Christian A, et al. 2016 European Guidelines on cardiovascular disease prevention in clinical practice: The Sixth Joint Task Force of the European Society of Cardiology and Other Societies on Cardiovascular Disease Prevention in Clinical Practice (constituted by representatives of 10 societies and by invited experts): Developed with the special contribution of the European Association for Cardiovascular Prevention\& Rehabilitation (EACPR), Eur. J. Prev. Cardiol. 2016, 23, NP1-NP96.
7. Bogdan W, Pawel G. The Health Situation of the Polish Population and Its Determinants; The National Institute of Public Health-National Institute of Hygiene: Warsaw, Poland, 2012.

8. Agnieszka D, Maciej P, Magdalena K, Krystyna $\mathrm{S}$, et al. Cardiovascular disease (CVD) risk factors in Krakow and in the whole Poland adult population. Results from the WOBASZ study and Polish arm of the HAPPIE project. Przegl. Epidemiol. 2015, 69, 79-86. [PubMed]

9. Ruohua Y, Wei L, Lu Y, Yang W, et al. Cardiovascular diseases and Risc-Factor Burden In Urban and Rural Communities in High, Middle and Low Income Region of China : A Large Community Based Epidemiology Study, J Am Heart Assoc. 2017;6:e04445. DOI:10.1161/ JAHA.116.004445.

10. Silvi S, Bharati V, Jude G, Fred P, et al. The social transition of risk factors for cardiovascular disease in the African region: evidence from three crosssectional surveys in the Seychelles. Int J Cardiol. 2013;168:1201-1206.

11. Sofiana N, Analysis of factors related to the quality of life of patients with chronic kidney disease undergoing hemodialysis at the Islamic Hospital of Fatimah Cilacap and the General Hospital in the Banyumas area. Tesis. Fakultas Ilmu Keperawatan Program Pasca Sarjana Kekhususan Keperawatan Medikal Bedah Universitas Indonesia, Depok, 2010.

12. Jana J, Schellberg D, Kraemer S, Haunstetter A, et al. Health Related Quality of Life in Patients with Congestive Heart Failure: Comparison with Other Chronic Diseases and Relation to Functional Variables, Heart 2002;87:235-241

13. Wei L, Hongqiu G, Koon KT, Jian B, Et al. Hypertension Prevalence, Awareness, Treatment, and Control in 115 Rural and Urban communities involving 47000 people from China. $J$ Hypertens. 
2016;34:39-46.

14. Ling RE, Liu F, Lu XQ, Wang W. Emerging issues in public health: a perspective on China's healthcare system. Public Health. 2011;125:9-14.

15. Indonesian Ministry of Health, Decree of the Minister of Health of the Republic of Indonesia No 854 of 2009 concerning Guidelines for Control of Heart and Blood Vessel Disease, Jakarta.

16. Ala A. (2011). Global Status Report on Noncommunicable Diseases 2010 Geneva, Switzerland: World Health Organization. Available at: http://apps.who.int/iris/ bitstream/10665/44579/1/9 789240686458_eng. pdf [Accessed 18 Nov. 2016]

17. Aryal KK, Neupane S, Mehata S, Vaidya A, et al. (2014). Non communicable diseases risk factors: STEPS Survey Nepal 2013. Kathmandu: Nepal Health Research Council.

18. Joko I, Sri PH, Dwi HT, Ingan UT, et al. Guidelines for Completing the 2018 Riskesdas Questionnaire, Badan Litbang Kesehatan, 2018, Jakarta.

19. Lily IR, Anna UR. (2014). Cardiovascular Disease in Women: The Challenges of the 21st Century. Badan Penerbit Fakultas Kedokteran Universitas Indonesia.

20. Wei WC, Run LG, Li SL, Man LZ, et al. (2017). China cardiovascular diseases report 2015: A summary. Journal of Geriatric Cardiology: $J G C, 14$ (1), 1-10. doi:10.11909/j.issn.16715411.2017.01.012

21. Asri M, Sujarwoto, Devarsetty P, Delvac O, et al. Cardiovascular Disease Risk Factor Prevalence and Estimated 10-year Cardiovascular Risk Scores in Indonesia : The SMART Health Extend Study, Plosone, 2019, https://doi.org/10.1371/ journal.pone.0215219
22. Vaidya A, Oli N, Aryal UR, Karki D, et al. (2014). Disparties in fruit and vegetable intake by Socio-demographic characteristics in periurban Nepalese adults.Journal of Kathmandu Medical College, 2(1),3-11.DOI : http://dx.doi. org/10.3126/jkmc.v2i1.10512

23. Ajeet SB, Pradeep KK, Neelam AT, Pooja $\mathrm{B}$, et al. Prevalence of hypertension and associated cardiovascular risk factors in Central India. Journal of Family and Community Medicine.2014; 21(1): 29. doi: 10.4103/22308229.128775

24. Ikechi GO, Innocent IC, Nicki T, Okechukwu OM, et al. (2013). Blood pressure gradients and cardiovascular risk factors in urban and rural populations in Abia State South Eastern Nigeria using the WHO STEPwise approach. PLoS One, 8(9), e73403. doi: http://dx.doi.org/10.1371/ journal.pone.0073403

25. Cholik HR, Laily I, Nurul SW. The Differences Cardiovascular Disease Risk Factors In Rural And Urban Population In District Ponorogo. Prosiding Seminar Hasil-Hasil Penelitian Dan Pengabdian Kepada Masyarakat 2015 Bidang : Sosial Politik, Ekonomi, Kesehatan, Pendidikan, Kajian Budaya, Dan Pengabdian Kepada Masyarakat. 2015; 342-355. Issn 978-602-0815$15-2$

26. Teesta B, Kyoung SL, Steven RB, Claudia H, et al. Limited Association Between Perceived Control and Health-Related Quality of Life in Patients with Heart Failure. J Cardiovasc Nurs. 2014 ; 29(3): 227-231. doi:10.1097/ JCN.0b013e31828b2b23.

27. Cholik HR, Laily I. (2013). Women's Vulnerability to Heart Disease and Stroke. Penelitian. Inpress

28. Martiningsih, Abdul H. 2019. Risk of Cardiovascular Disease in Chronic Disease 
Medico-legal Update, January-March 2022, Vol.22, No. 1133

Management Program Participants (Prolanis) at the Bima City Health Center: Correlation with the Ankle Brachial Index and Obesity, Jurnal Keperawatan Indonesia, 2019; 22 (3): 200-8. DOI: $10.7454 /$ jki.v22i3.880

29. Thang SH, Mike EJL. (2016). A Clinical Perspective of Obesity, Metabolic Syndrome and Cardiovascular Disease. JRSM Cardiovascular Disease, 25(5). https://doi.org/10. 1177/2048004016633371.

30. Seongkum H, Terry AL, Chizimuzo O, Debra KM. Quality of Life in Patients With Heart Failure: Ask the Patients. Heart Lung. 2009 ; 38(2): 100108. doi:10.1016/j.hrtlng.2008.04.002 